\title{
Ullrich congenital muscular dystrophy: Report of nine cases from India
}

\author{
A. N alini, N. Gayathri ${ }^{1}$, Vani Santosh ${ }^{1}$ \\ Departments of Neurology and ${ }^{1}$ Neuropathology, National Institute of Mental Health and Neurosciences, Bangalore, India
}

Address for correspondence:

Dr. A. Nalini,

Department of Neurology,

National Institute of M ental Health

and Neurosciences, Hosur Road,

Bangalore - 560 029, India.

E-mail: atchayaramnalini@yahoo.

co.in

DOI: $10.4103 / 0028-3886.48820$

\begin{abstract}
Background: Ullrich congenital muscular dystrophy (UCMD) is a unique congenital disorder characterized clinically by generalized muscle weakness, contractures of the proximal joints and hyperextensibility of the distal joints and begins from birth or early infancy. M aterials and M ethods: We prospectively evaluated nine cases of classical UCM D and recorded the clinical phenotypic characteristics and the histopathological findings. Results: There were eight boys and one girl child with classical features of severe muscle weakness, prominent proximal contractures, distal hyperlaxity and prominent calcanei. Immunohistochemistry for Collagen VI AI done on seven cases showed total absence of labeling in six while sarcolemmal-specific deficiency was noted in one case confirming the diagnosis of UCMD. Interestingly, all our patients were noted to have near total absence of major palmar and plantar creases, and instead there were fine mesh-like lines in addition to the soft velvety skin on the palms and soles suggestive of altered collagen arrangements in the skin. Hitherto, this clinical finding has not been described in UCMD in the English literature.
\end{abstract}

Key words: Collagen VI, Col6A, Ullrich congenital muscular dystrophy

\section{Introduction}

Ullrich disease or Ullrich congenital muscular dystrophy (UCMD) was first described in 1930 as an unusual form of congenital muscular dystrophy in two boys and called as congenital hypotonic-sclerotic muscular dystrophy. ${ }^{[1]}$ The predominant clinical manifestations include generalized muscle weakness and wasting, prominent contractures of the proximal joints and hyperextensibility of the distal joints from infancy and a progressive course. The other characteristic feature is prominent calcanei and normal intelligence. Complete deficiency or reduction of Collagen VI protein has been demonstrated in skeletal muscle in Ullrich CMD ${ }^{[2-6]}$ Molecular genetically frame shift mutations in the gene encoding Collagen VI alpha 2 (COL6A2) has been described. ${ }^{[2,3,7,8]}$ We report nine children with UCMD with deficiency of Collagen VI A1 protein confirmed by immunohistochemistry.

\section{M aterials and M ethods}

Prospective analysis of nine patients with UCMD by clinical, histopathological and immunohistochemical study was undertaken. Clinical data including perinatal complications and problems, age of onset and progression of weakness, wasting and contractures in all patients. A detailed pedigree diagram was created for all. Written informed consent was obtained from the parents for their children to undergo investigations and for publication of their photographs. Muscle biopsy done on seven cases was subjected to a battery of enzyme (SDH, NADH-Tr, ATPase pH 9.4,4.6, acid phosphatsase) and nonenzyme (HE,MGT,PAS) stains. Immunohistochemistry to monoclonal antibodies against dystrophin $(1,2,3)$, sarcoglycans $(\alpha, \beta, \gamma, \delta), \alpha 2$ laminin, $\beta$ - dystroglycan (NCL, UK) and Collagen VI A1 (Santa Cruz, Europe) as primary and LSAB + (DAKO) as secondary was carried out.

\section{Results}

Over the last two years (2005 to 2008), nine children from seven families with classical phenotype of UCMD were studied. There were eight boys and one girl child 
and all had symptoms from birth. Consanguinity was present in five families. The mean age at diagnosis was 4.5 years (range 1-8). All were observed to have contractures at birth. Grossly, delayed motor milestones were present and none attained ability to stand or walk independently. All had attained neck control and were able to sit with support. The details of the clinical picture and laboratory findings in each patient are represented in Table 1. Higher mental functions were normal and appropriate for the age. The patients had failure to thrive and the weight was below the $25^{\text {th }}$ percentile. Abnormal facial characteristics, bifacial weakness, thin habitus with generalized muscle wasting were seen in all patients. Classical protuberant calcanei were noted in all. Distal wasting appeared more prominent than proximal with severe weakness, proximal more tan distal including truncal muscles. Deep tendon reflexes were absent. Contractures were present at the shoulders, elbows, hips and knees. Hyperlaxity was evident at the wrists, fingers, ankles and toes. Seven had rigidity of the spine with moderate to severe kypho-scoliosis [Figure 1a-g]. The scoliosis was progressive. Two patients had early respiratory failure. All patients had the typical velvety palms and soles and almost total absence of the major palmar and plantar creases. Instead there were fine lines with a mesh-like appearance [Figure 2a, Figure 2b]. Creatine kinase level was normal in seven and minimally elevated in one. ECG and 2D echocardiogram were normal in all. EMG showed myopathic process. Brain magnetic resonance imaging (MRI) done in three patients was normal. Muscle biopsy revealed dystrophic features with mild to moderate numbers of atrophic fibers with pyknotic nuclei in all. In addition, a few lobulated fibers and Type 1 fiber predominance were noted in three cases (Cases 4, 8 and 9). Immunostaining to Collagen VI A1 (COL 6A1) was totally absent in six of the seven cases while sarcolemmal- specific deficiency was seen in one (Case 1). There was no deficiency of dystrophin, sarcoglycans, merosin, dysferlin, or beta dystroglycan [Figure 3a-h].

\section{Discussion}

The present study reveals nine children with classical phenotype of UCMD, confirmed immunohistochemically by deficiency of COL 6A1. Typically, all shared a similar clinical history with onset in infancy, characteristic facial appearance, proximal contractures, distal hyperextensibility of joints, protuberant calcanei, delayed motor milestones, generalized muscle wasting with weakness and normal mental functions and dystrophic features on muscle biopsy. Collagen VI, a ubiquitous extracellular matrix protein, forms a microfibrillar network in association with basement
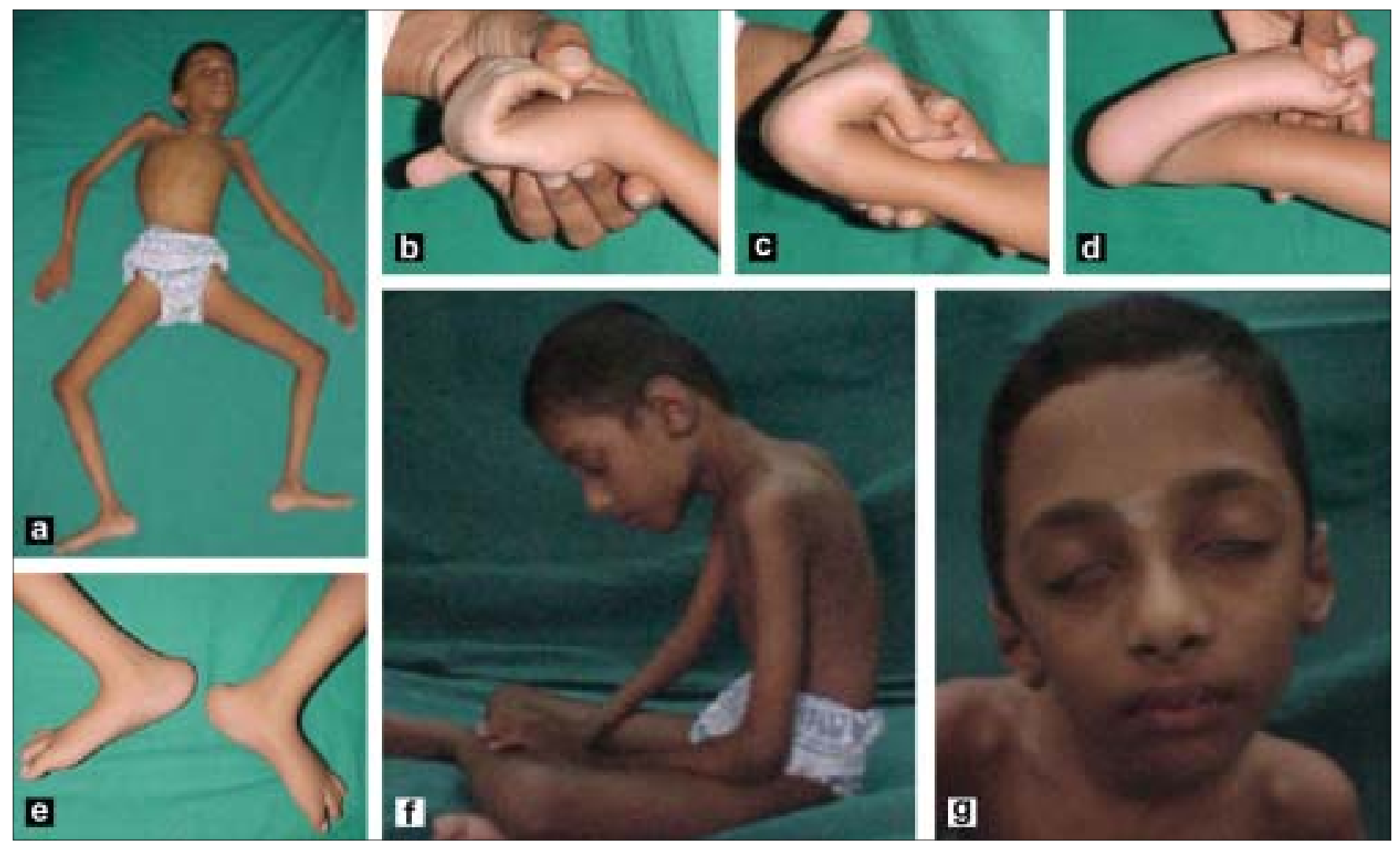

Figure 1: (a) Severe contracture of the shoulder, elbow joints, hips and knee joints, slender habitus with generalized muscle wasting and particularly of distal upper limb. (b) Hyperextensibility of the interphalangeal joints. (c) Hyperlaxity of the wrist joint. (d) Hyperextensibility of the ankle. (e) Classical protuberant calcanei. (f) Nuchal contracture. (g) Abnormal facial characteristics with bifacial weakness 


\begin{tabular}{|c|c|c|c|c|c|c|c|c|c|}
\hline Parameters & Case 1 & Case 2 & Case 3 & Case 4 & $\begin{array}{l}\text { Case } 5 \\
\text { (sister of } \\
\text { case 4) }\end{array}$ & Case 6 & Case 7 & $\begin{array}{c}\text { Case } 8 \\
\text { (brother of } \\
\text { case } 7\end{array}$ & Case 9 \\
\hline Age at diagnosis (yrs) & 6 & 4 & 4 & 3 & 1 & 5 & 6 & 4 & 8 \\
\hline Consanguinity & - & _ & + & + & + & + & + & + & + \\
\hline $\begin{array}{l}\text { Recurrent lower } \\
\text { respiratory infections }\end{array}$ & + & - & + & - & - & - & - & - & - \\
\hline Respiratory difficulty & + & _ & _- & _- & _- & _- & - & _- & _ \\
\hline $\begin{array}{l}\text { Abnormal facial } \\
\text { characteristics }\end{array}$ & + & + & + & - & - & + & + & + & + \\
\hline Contractures at birth & + & + & + & _- & + & + & + & + & + \\
\hline $\begin{array}{l}\text { Soft velvety palmar and } \\
\text { plantar skin }\end{array}$ & + & + & + & + & + & + & + & + & + \\
\hline $\begin{array}{l}\text { Scoliosis } \\
\text { Contractures }\end{array}$ & + & + & + & - & - & + & + & + & + \\
\hline Spine & + & + & + & _- & _- & + & + & + & + \\
\hline Shoulder & + & + & + & - & - & + & _- & + & + \\
\hline Elbow & + & + & + & + & + & + & $\overline{+}$ & + & + \\
\hline Hips & + & + & + & - & - & + & + & + & + \\
\hline Knees & + & + & + & + & + & + & + & + & + \\
\hline $\begin{array}{l}\text { Distal joint } \\
\text { hyperextensibility }\end{array}$ & + & + & + & + & + & + & + & + & + \\
\hline Wrist & + & + & + & + & + & + & + & + & + \\
\hline Interphalangeal & + & + & + & + & + & + & + & + & + \\
\hline Ankle & + & + & + & + & + & + & + & + & + \\
\hline Toes & + & + & + & + & + & + & + & + & + \\
\hline Kyphoscoliosis & Severe & Mild & Mild & _ & _- & Moderate & Mild & + & Moderate \\
\hline $\begin{array}{l}\text { Abnormal palmar and } \\
\text { plantar creases }\end{array}$ & + & + & + & + & $\overline{+}$ & + & + & + & + \\
\hline $\begin{array}{l}\text { Generalized severe } \\
\text { muscle wasting }\end{array}$ & + & + & + & - & - & + & - & + & + \\
\hline $\begin{array}{l}\text { Facial weakness } \\
\text { (moderate to severe) }\end{array}$ & + & + & + & + & + & + & + & + & + \\
\hline Prominent ears & + & + & - & _ & - & + & & & \\
\hline Creatine kinase (units/L) & 164 & 198 & 233 & $3 \overline{18}$ & 107 & 110 & $1 \overline{23}$ & 116 & 255 \\
\hline Histopathology & Dystrophy & Dystrophy & Dystrophy & $\begin{array}{l}\text { Dystrophy } \\
\text { lobulated fibers and } \\
\text { Type } 1 \text { predominance }\end{array}$ & Not done & Dystrophy & $\begin{array}{l}\text { Not } \\
\text { done }\end{array}$ & $\begin{array}{l}\text { Dystrophy } \\
\text { lobulated fibers and } \\
\text { Type } 1 \text { predominance }\end{array}$ & $\begin{array}{l}\text { Dystrophy } \\
\text { lobulated fibers and } \\
\text { Type } 1 \text { predominance }\end{array}$ \\
\hline Immunostaining & $\begin{array}{l}\text { Sarcolemmal-specific } \\
\text { deficiency }\end{array}$ & $\begin{array}{c}\text { Total } \\
\text { absence }\end{array}$ & $\begin{array}{c}\text { Total } \\
\text { absence }\end{array}$ & Total absence & Not done & $\begin{array}{c}\text { Total } \\
\text { absence }\end{array}$ & $\begin{array}{l}\text { Not } \\
\text { done }\end{array}$ & Total absence & Total absence \\
\hline
\end{tabular}


membrane around muscle cells. Mutations in gene encoding Col 6 leading to total / partial loss of Col 6 results in loss of integrity between the basal lamina and
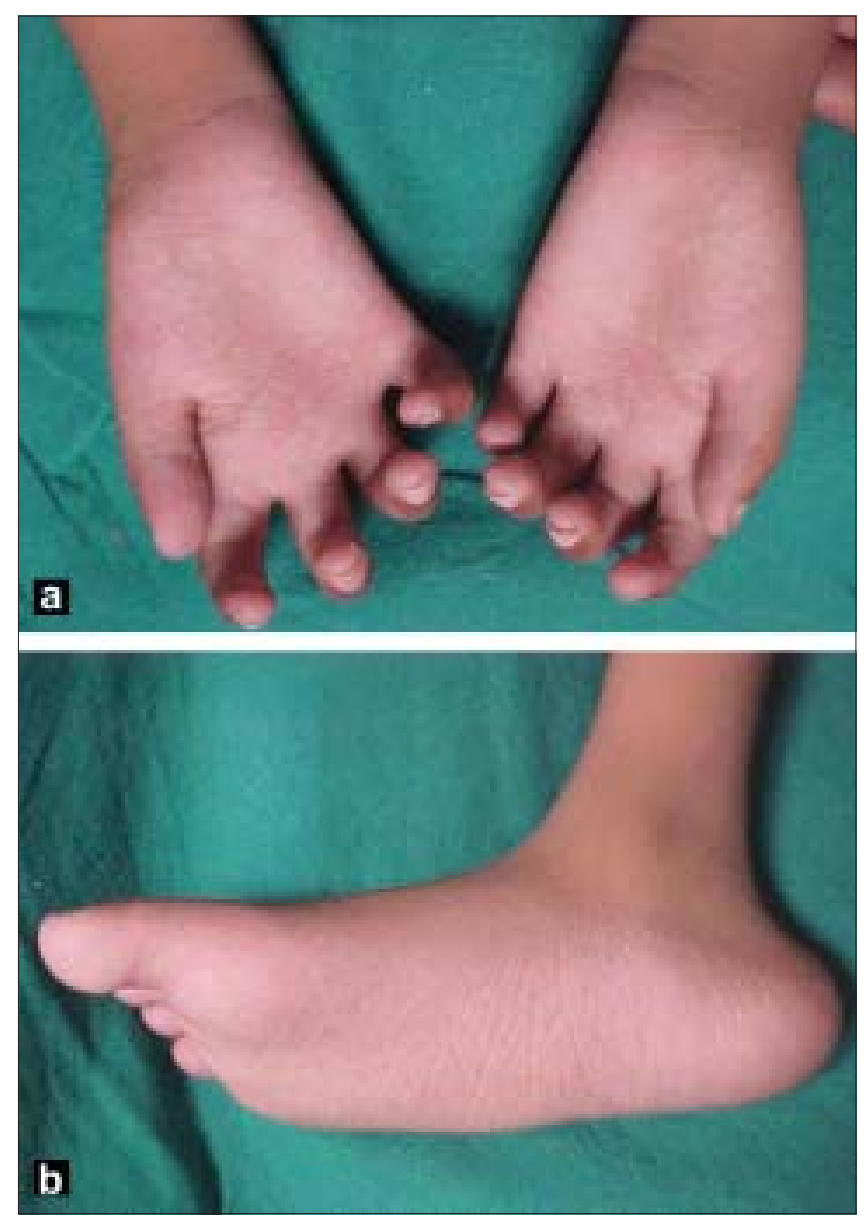

Figure 2 a,b: Photographs of the palms and soles showing almost total absence of palmar and plantar creases with smooth skin the interstitium. ${ }^{[9,10]}$

It is reported that patients with UCMD have soft velvety palms and soles. ${ }^{[11]}$ All our patients had this classical soft and velvety skin on the palms and soles. Interestingly, the major proximal, middle and distal creases were absent and there were mesh-like fine creases on the palms and soles. Hitherto, this finding has not been described in the reports in English literature. Collagen provides a framework that gives the tissues their form and strength. ${ }^{[12]}$ It has been demonstrated that alteration in the control mechanisms can change the balance between synthesis and degradation of collagen, thus leading to either excessive deposition or depletion of collagen. Several collagen disorders result from defects in the formation of cross-links. ${ }^{[13]}$ It is possible that abnormalities in the packing of collagen molecules into a fiber or in the interaction of collagen fibers with other extracellular components of connective tissue may be the cause for the significantly reduced dermal creases in our patients.

Morphologically, muscle biopsy revealed dystrophic features in all. Immunostaining to Col 6 A1 showed total absence of the protein in five patients. This finding was similar to those reported previously. ${ }^{[5,8,11]}$ In one patient there was sarcolemmal-specific deficiency (SCCD). This finding has been reported by Kawahara et al., wherein a heterozygous Col 6A1 Glycine substitution that influences cell attachment in fibroblasts causes SCCD. ${ }^{[14]}$ It is known that in some patients with the UCMD phenotype, the role of Collagen VI molecules has been excluded, suggesting genetic heterogeneity for this disorder. ${ }^{[7]}$ Hence, in our cases the clinical and immunohistochemical diagnosis is UCMD with a pending genetic confirmation. Thus, final diagnosis
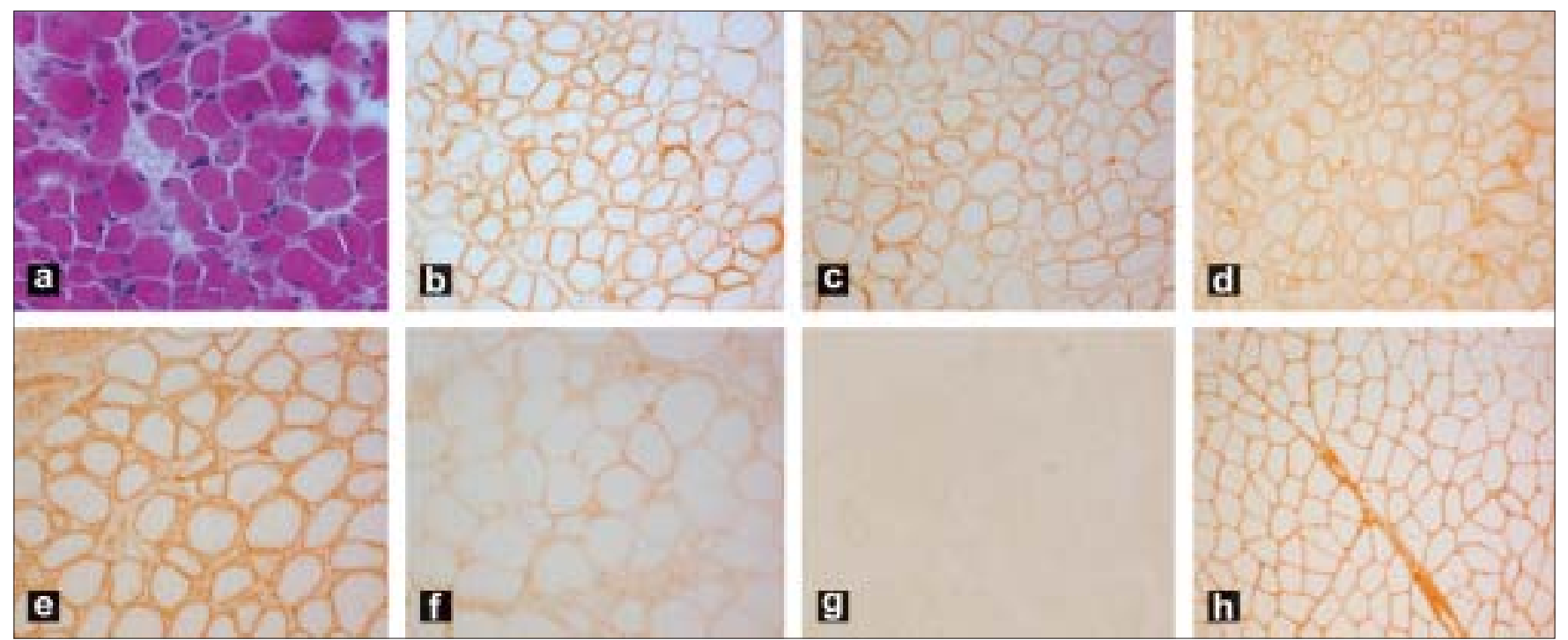

Figure 3: (a) Muscle biopsy showing dystrophic features, (b) (HE). Immunostaining to antibodies against dystrophin, (c) $\alpha$-sarcoglycan, (d) $\alpha 2$ laminin, (e) and $\beta$-dystroglycan (f) show positive labeling along the membrane. Note: Sarcolemmal-specific deficiency (g) and complete deficiency (h) of Col6A 1. Normal control for Col 6A 1 
requires molecular genetic testing, which is currently available only at a few medical centers in the world.

Treatment for UCMD is largely supportive and depends on the intensity of the severity of symptoms and age at onset. Children with severe UCMD require early mobilization in a standing frame to achieve upright posture and protect against scoliosis and contractures. Regular stretching and splinting are useful. Scoliosis surgery may be required later in life. There are presently no definite / specific therapeutic options but supportive treatment is known to dramatically improve the longevity and quality of life..$^{[11]}$

A turning point in basic research on Collagen VI myopathies is the discovery of mitochondrial dysfunction seen in Col6a1 null mice. Treatment of Col6a1(-/-) mice with cyclosporine A rescued the mitochondrial dysfunction and decreased apotosis. ${ }^{[15]}$ Similar mitochondrial defects were revealed in cultures of UCMD patients and myoblasts from patients affected with UCMD displayed functional and ultrastuctural mitochondrial alterations. ${ }^{[16]}$ Closely following this an open pilot trial with cyclosporine A in five patients with UCMD was reported. Before treatment all patients displayed mitochondrial dysfunction and increased frequency of apotosis, as determined in muscle biopsies. Both these pathologic signs were largely normalized after one month of oral cyclosporine A administration, which also increased muscle regeneration. ${ }^{[17]}$ These findings demonstrate that drugs acting on the pathogenic mechanism represent an important proof for potential therapy in genetic disorders like UCMD.

For families where the muscle biopsy of the proband shows absence of Collagen VI immunolabeling, examination of chorionic villus biopsy along with linkage analysis, offers a potential route for prenatal diagnosis even if the causative mutation is not known in the family. ${ }^{[11]}$ Thus, identifying this form of CMD is of importance to the families if there is an opportunity for prenatal diagnosis.

\section{References}

1. Ullrich O. kongenitale, atonish-sklerotische Muskeldystrophie, ein weiterer Typus der heredodegenerativen Erkrankungen des neuromuskularen Systems. Z Ges Neurol Psychait 1930;126:171-201.

2. Camacho Vanegas O, Bertini E, Zhang RZ, Petrini S, Minosse C, et al. Ullrich scleroatonic muscular dystrophy is caused by recessive mutations in collagen type VI. Proc Natl Acad Sci USA 2001;98:7516-21.

3. Higuchi I, Shiraishi T, Hashiguchi T, Suehara M, Niiyama T, Nakagawa M, et al. Frame-shift mutations in the collagen VI gene causes Ullrich's disease. Ann Neurol 2001;50:261-5.

4. Ishikawa H, Sugie K, Murayama K, Awaya A, Suzuki Y, Noguchi S, et al. Ullrich disease due to deficiency of collagen VI in the sarcolemma. Neurology 2004;62:620-3.

5. Mercuri E, Yuva Y, Brown SC, Brockington M, Kinali M, Jungbluth H, et al. Collagen VI involvement in Ullrich syndrome. Neurology 2002;58:1354-9.

6. Tetreault M, Duquette A, Thiffault I, Bherer C, Jarry J, Loisel L, et al. A new form of congenital muscular dystrophy with joint hyperlaxity maps to 3p23-21. Brain 2006;129:2077-84.

7. Demir E, Sabatelli P, Allamand V, Ferreiro A, Moghadaszadeh B, Makrelouf M, et al. Mutations in COL6A3 cause severe and mild phenotypes of Ullrich congenital muscular dystrophy. Am J Hum Genet 2002;70:1446-58.

8. Baker NL, Morgelin M, Peat R, Goemans N, North KN, Bateman JF, et al. Dominant collage VI mutations are a common cause of Ullrich congenital muscular dystrophy. Hum Mol Genet 2005;14:279-93.

9. Kuo HJ, Maslen CL, Keene DR, Glanville RW. Type VI collagen anchors endothelial basement membranes by interacting with type IV collagen. J Biol Chem 1997;272:26522-9.

10. Ishikawa H, Sugie K, Murayama K, Ito M, Minami N, Nishino I, et al. Ullrich disease: Collagen VI deficiency: EM suggests a new basis for muscular weakness. Neurology 2002;59:920-3.

11. Lampe AK, Bushby KM. Collagen VI related muscle disorders. J Med Genet 2005;42:673-85.

12. Delvin TM. Diseases of collagen synthesis. In: Delvin TM, editor. Text book of biochemistry with clinical correlations. Wiley-Liss. A John Wiley and sons, Ine; 2006. p. 100-4.

13. Bhagavan NV. Heteropolysaccharides II: Proteoglycans. In: Bhagavan NV, editor. Medical biochemistry. San Diego, California: Academy Press; 2002. p. 173-95.

14. Kawahara G, Okada M, Morone N. A heterozygous COL 6A1 glycine substitution that influences cell attachment in fibroblasts causes sarcolemmal - specific collagen VI deficiency (SSCD). Neuromuscul Disord 2006; $16: 84$

15. Angelina A, Tiepolo T, Sabatelli P, Grumati P, Bergamin N, Golfieri C, et al. Mitochondrial dysfunction in the pathogenesis of Ullrich congenital muscular dystrophy and prospective therapy with cyclosporins. Proc Natl Acad Sci USA 2007;104:991-6.

16. Merlini L, Angelin A, Teipolo T, Braghetta P, Sabatelli P, Zamparelli A, et al. Cyclosporin A corrects mitochondrial dysfunction and muscle apotosis in patients with collagen VI myopathies. Proc Natl Acad Sci USA 2008;105:5225-9.

17. Merlini L, Bernardi P. Therapy of collagen VI-related myopathies (Bethlem and Ullrich). Neurotherapeutics 2008;5:613-8.

Accepted on 07-02-2009

Source of Support: Nil, Conflict of Interest: None declared. 